\title{
EL PAGO DE INTERÉS EN EL SISTEMA FINANCIERO Y LA AFECTACIÓN A LA TUTELA JURÍDICA DE USUARIOS DE CRÉDITOS DE CONSUMO
}

\author{
CARLOSESMITHMENDOZA GARCÍA*
}

\begin{abstract}
Resumen
El presente artículo trata sobre el pago de intereses y su vinculación con la tutela de usuarios de créditos de consumo en Perú. La legislación peruana regula regímenes legales diferentes tanto para personas ajenas al sistema financiero, a las cuales establece límites en el pacto de intereses, como para las Empresas del Sistema Financiero Nacional, las que gozan de un tratamiento preferente, al estar facultadas para pactar intereses $\sin$ someterse a topes máximos. Este último régimen normativo no se condice con la tutela jurídica de los usuarios de los créditos de consumo, al no tomar en cuenta las evidentes asimetrías económicas, de información y de negociación existentes en el mercado financiero, que genera que los usuarios se encuentren en evidente desventaja frente a las empresas del Sistema Financiero, lo cual conlleva a la existencia de tasas de intereses excesivas, generando desequilibrio en las prestaciones derivadas de estos contratos y legitimando, de este modo, la mala fe en las prácticas comerciales del sistema financiero.
\end{abstract}

Palabras clave: Pago de intereses, tasas de interés, interés, créditos de consumo, mercado financiero.

\begin{abstract}
The present article deals with interest payment and its link with the consumption credits users guidance in Peru. The Peruvian legislation regulates different legal regimes, for people outside the financial system, establishing limits in the interest agreement and also for the National System Enterprises that have a preferential treatment; They are be empowered to negotiate interests without being subject to maxim top amounts. This last regulatory regime is in disagreement with the consumption credits users protection because they don't take into account the evident disadvantages in which are such users; the regimen mentioned above leads to excessive interest rates, generating imbalance in the benefits derived from the contracts and the legitimization of the bad faith in the financial system commercial practices.
\end{abstract}

* Maestro en Derecho y Ciencias Políticas, con mención en Derecho Civil y Comercial, por la Universidad Nacional de Trujillo. Actualmente ejerce funciones como juez titular del Juzgado Mixto de Corongo de la CorteSuperior de Justicia del Santa. 
Keywords: Interest payment, interest rate, interest, consumption credit, financial market.

\section{Sumario}

1.- Introducción. 2.- El pago de intereses. 2.1.- Noción de interés. 2.2.-Importancia del interés. 2.3.- Clases de interés. 2.4.- Las tasas de interés. 3.-El pago de intereses para personas ajenas al sistema financiero. 4.- El pago de intereses dentro del Sistema Financiero. 5.- El crédito de consumo. 5.1.-Definición. 5.2.- Principios que sustentan la tutela de los usuarios de créditos de consumo. 6.- Tasas de interés, transparencia y tutela de los usuarios de créditos de consumo. 7.- Libertad para fijar tasas de interés y tutela de los usuarios de créditos de consumo. 8.- Conclusiones. 9.- Bibliografia.

\section{Introducción}

El pago de intereses es una institución del derecho de obligaciones, con una gran trascendencia en la realidad económica actual, pues su estipulación forma parte de casi la totalidad de contratos de crédito celebrados en el ámbito civil y comercial, teniendo un papel importante en la contribución al crecimiento económico del país.

Por ello, su estudio no solo debe enfocarse desde el punto de vista de los economistas, sino también desde el punto de vista jurídico, por cuanto nuestra disciplina no puede ser ajena a las implicancias que derivan de tan trascendente institución. Nótese que el pago de intereses ha sido estudiado y regulado desde la antigüedad, como acotan MORALES, FLORES y YANEZ, los primeros antecedentes conocidos aparecen en la antigua India en el año 2000 AC, existiendo abundantes referencias entre las que destacan las alusiones condenatorias existentes en los libros sagrados (Antiguo Testamento y Corán), y en los discursos de filósofos clásicos como Aristóteles, Platón y San Agustín. En ellas, la posición doctrinaria dominante respecto al tema, es que debe haber un precio justo por el uso del dinero, y que es condenable cualquier cobro por encima de él ${ }^{1}$.

FLORES, Carolina; MORALES, Liliana y Álvaro YÁÑEZ, (2005). Interés Máximo Convencional. Origen Evolución y forma de cálculo, en http://www.sbif.cl/sbifweb//internet/archivos/publicacion_4193.pdf, consulta: 15 de diciembre de 2015. 
OSTERLING y CASTILLO², haciendo referencia al tratamiento del pago de intereses en el Derecho Romano, anotan lo siguiente:

El mutuo en un inicio fue gratuito, (...) no obstante la gratuidad del mutuo, fue posible establecer un pacto adicional para el cobro de intereses, al que se le llamó 'stupulatio usurarum'. Dicho 'pactum' fue admitido en los préstamos de grano y solo tiempo después en los préstamos de dinero hecho por los banqueros; esto último, como reconocimiento a la actividad bancaria. Además, se admitió que la cuantía de los intereses fuese fijada en razón del riesgo que la operación realizada pudiese importar. El cobro de intereses generó en Roma constantes reclamos, pues el monto de aquellos llegó a ser impresionante; por ello fueron diversas las normas dictadas. Estas disposiciones intentaron ordenar el devengamiento de los intereses y prohibir la capitalización de los mismos. Entre dichas normas se puede citar a las leyes licinas sextias del año 367, la lex duilia menenia del año 347, la lex genucia del año 342, la lex procia del año 118, la lex Marcia del año 104 y la lex Comelia pompeia unciaria del año 88, todas ella A.C.

Teniendo en cuenta estos antecedentes, debe atenderse a que el estudio y reflexión del Derecho se orienta a la búsqueda de la justicia en las relaciones jurídicas establecidas entre los ciudadanos; por tanto, el Derecho no puede permanecer indiferente ante la realidad económica.

Según índices económicos, el crédito de consumo viene registrando un considerable aumento en los últimos años, conforme lo señalan diversas notas informativas emitidas por el Banco Central de Reserva del Perú - en adelante BCRP-. En una última nota informativa publicada en el portal web de esta Institución, se hace conocer que el crédito al sector privado en moneda nacional - que incluye el otorgado por la banca, financieras y cajas municipales y rurales - registro un aumento de 29,2 por ciento en noviembre de 2015, respecto a similar mes de $2014^{3}$. Es decir, se trata de un sector de gran dinamismo y que, por tanto, involucra a un gran número de personas que realizan operaciones y con ello coadyuvan al crecimiento de la economía. Sin embargo, no todo es color de rosa, pues al respecto se ha

2 Osterling PARODI, Felipe y Mario CASTLlo Freyre (1996). Tratado de las Obligaciones. Volumen XVI (2 Parte-Tomo V). Lima: Fondo Editorial PUCP, p. 260.

3 Banco Central de Reserva del Perú (2015, 27 de diciembre). Nota Informativa, en http://www.bcrp.gob.pe/docs/Transparencia/Notas-Informativas/2015/nota-informativa2015-12-27.pdf, consulta: 22 de enero de 2016. 
puesto en evidencia prácticas abusivas por parte de las Empresas del Sistema Financiero Nacional - en adelante ESFN -, que afectarían a los usuarios de créditos de consumo, debido a las elevadas tasas de interés que se cobran dentro del sistema financiero.

Así, en una nota periodística publicada por el diario "La República”, el día 23 de noviembre de 2010, el especialista Miguel Ángel Martín, profesor de ESAN, sostiene que muchas veces se engaña a los clientes con la publicidad, pues se les plantea la tasa de interés, pero no la tasa de costo efectivo, que es lo que realmente pagan; asimismo indica que el problema de las altísimas tasas de interés que se cobran en el mercado peruano es la falta de competencia interbancaria y recordó que en el Perú el 75\% del mercado crediticio se concentra en tres bancos. Agrega que somos el país de mayor concentración bancaria en toda Latinoamérica, lo cual genera conductas oligopólicas; es decir, altas tasa de interés, altas comisiones y poca competencia 4 .

Basta corroborar la información publicada en el portal web de la Superintendencia de Banca y Seguros - en adelante SBS -, para advertir la vigencia de tasas de interés considerablemente elevadas que las ESFN aplican a los créditos de consumo, apreciándose del reporte de tasa de interés promedio, la vigencia de tasas para créditos de consumo que, en algunos casos, superan el $200 \%$ anual.

Las prácticas antes descritas, se encuentran amparadas en una normatividad que permite a las ESFN fijar libremente y sin topes tasas de interés, comisiones y gastos que aplican a sus operaciones activas y pasivas. Es decir, las empresas del Sistema Financiero, al no tener límite alguno para señalar tasas de interés que cobran a sus usuarios, gozan de un tratamiento preferente; sin embargo, cabe preguntarse: ¿el tratamiento normativo que faculta el pago de intereses sin topes a favor de las ESFN, contraviene la tutela de los usuarios de créditos de consumo?

Justamente al tratar de responder esta pregunta nos avocaremos, para lo cual se estudiará los regímenes legales que regulan el pago de intereses y sus implicancias en el derecho de los consumidores y usuarios.

Precisamos que la intención del presente trabajo es coadyuvar a soluciones más justas en las relaciones de consumo $\mathrm{y}$, de este modo, se busca

4 Cfr:: La República (2010, 23 de noviembre). Advierten sobre tasas de interés, p. 17. 
contrapesar en las evidentes asimetrías existentes entre las partes celebrantes de este tipo de contratos.

\section{El pago de intereses}

\subsection{Noción de interés}

DÍAZ5 afirma que el Interés "se define como el rendimiento paulatino que devenga un capital, en función de su importe y al tiempo transcurrido, sea como retribución por el uso del dinero o como compensación por la demora en el pago." Destaca las siguientes características de los intereses:

"i) Son frutos o productos;

ii) Se deben en virtud a una relación obligatoria, ya sea contractual o legal;

iii) Constituyen una deuda de carácter pecuniario, es decir los intereses deben ser pagados en dinero;

iv) Presuponen la existencia de una acreencia sujeta a rendimiento; este es un requisito inherente a todo supuesto, ya que si no hay acreencia no puede haber un interés;

v) Son una obligación de carácter accesorio a la obligación principal de entrega o devolución de capital."

Para Diez Picazo, citado por FERNÁNDEZ6, el interés, en términos económicos, es el "precio o la remuneración que una persona ha de pagar por la utilización o disfrute de bienes de capital de pertenencia ajena. Como quiera que los bienes de capital constituyen factores de producción, su utilización o disfrute proporciona un beneficio, por el cual debe pagarse un precio. En términos jurídicos, sin embargo, el concepto de 'interés' es un concepto más estricto. Jurídicamente son intereses las cantidades de dinero que deben ser pagados por la utilización y disfrute de un capital, consistente también en dinero".

5 DíAZSILVA, Nathalie (2005). Las tasas de interés aplicables a las operaciones no financieras ¿Cómo se regulan los intereses en el Perú? Revista Actualidad Jurídica. Nº136, Lima, p. 55.

6 FERNANDEZ FERNÁNDEZ, César (2007). Interés compensatorio y moratorio. En AA.VV. Código Civil Comentado. Tomo VI, Lima: Gaceta Jurídica, p. 407. 


\subsection{Importancia del interés}

VILLEGAS y SCHUJMAN7, acotan que "la primera función de los intereses en una economía de mercado es la de establecer un equilibrio entre el consumo presente y el consumo futuro (ahorro).

Asimismo, el interés tiene diversas funciones en la economía, las mismas que pasamos a anotar:

a) Los intereses establecen el equilibrio entre la oferta y la demanda de fondos prestables.

b) Los intereses influyen en la política monetaria, incentivando o conteniendo el proceso económico.

c) Los tipos de interés pueden influir en el volumen de ahorro y en particular puede observarse que con tipos de interés negativos se agudizan los procesos de desmonetización.

d) Los intereses distribuyen los fondos prestables entre los distintos usuarios, de manera que los ahorros escasos se distribuyen entre aquellos proyectos de inversión cuya tasa de retorno no sea mayor a los niveles de interés".

\subsection{Clases de interés}

Para fines del presente trabajo tomaremos la clasificación según su finalidad, que se encuentra recogida expresamente en el Código Civil.

a) Interés compensatorio: El interés es compensatorio cuando constituye la contraprestación por el uso del dinero o de cualquier otro bien. Tiene como finalidad el de mantener el equilibrio patrimonial, evitando que una de las partes obtenga un enriquecimiento al no pagar el importe del rendimiento de un bien. Así, se permite cobrarle a quien se beneficia del dinero o cualquier otro bien, una retribución adecuada por el uso que haga de él 8 .

b) Interés moratorio: Según el artículo $1242^{\circ}$ del Código Civil, "tiene por finalidad indemnizar la mora en el pago". Para

7 VILLEGAS, Carlos y Mario SchujMan. Intereses y Tasas. Abeledo Perrot. Buenos Aires. Citado por OSTERLING PARODI, Felipe y CASTILLOFREYRE, Mario. Op. cit., p. 298.

8 Cfr. FerREROCOsta, Raúl. Curso de derecho de Las Obligaciones. Lima: Grijley, 2001, p. 212. 
DÍAZ", "los intereses moratorios constituyen una sanción o penalidad que tiene por objeto resarcir al acreedor los daños y perjuicios que el deudor le causa con el incumplimiento tardío de su obligación". Precisa que "los daños y perjuicios causados al acreedor no requieren ser probados a fin de que opere la obligación de pagar intereses moratorios. Por el contrario, en la mora los daños y perjuicios se presumen juris et de jure. La razón es que todo capital sujeto a rendimiento, por su propia naturaleza, genera frutos por el transcurso del tiempo, por lo que el solo hecho del retardo en el pago del mismo importa la privación de réditos al acreedor, es decir un daño y perjuicio que debe ser resarcido. (...)". Agrega que "no basta con que el deudor simplemente incurra en un retraso para que los intereses moratorios se devenguen. Además del retraso per se (elemento objetivo), es necesario que el mismo sea imputable al obligado y sea también antijurídico, es decir, que obedezca a culpa, ya sea leve o grave, o dolo por parte de obligado (elemento subjetivo). (...) Adicionalmente el Código Civil exige la intimación (elemento formal) para que se configure la mora, la cual consiste en que el acreedor le haya requerido al deudor judicial o extrajudicialmente, el cumplimiento de su obligación, salvo en aquellos casos en que el código taxativamente señala que no se requiere intimación, y que, por lo tanto, la mora es automática." 10

\section{$2.4 \quad$ Las tasas de interés}

Una tasa de interés es el precio del dinero. También es definido como el porcentaje que paga el prestatario por el capital tomado en calidad de préstamo ${ }^{11}$.

Existe una diversidad de tasas de interés; pero, por ser didáctica, recogemos una clasificación elaborada por KEIL ${ }^{12}$ quien refiere que las tasas de interés pueden ser:

\footnotetext{
DíAZSILVA, Nathalie. Op. cit. p. 55.

Ibídem, p.56.

11 Falconí Picardo, Marco y Angelina Falconí PiCARDO. Diccionario de Banca, Finanzas y Empresa, Grijley, Lima, 2002, p. 262.

12 Cfr. KeIL, Roberto. Lecciones de Derecho Monetario. Rentería Editores SAC, Lima, 2004, pp. 191196.
} 
a) Activas y pasivas. Las primeras son las que los intermediarios financieros cobran por el dinero que prestan, las segundas se refieren a las que estas entidades pagan por los depósitos que reciben.

Usualmente los depósitos son remunerados con una tasa menor que aquellas aplicables a los créditos. La diferencia entre ambas constituye el "spread" o margen financiero, o utilidad financiera.

b) Tasa nominal y Tasa real. Es nominal (o tasa ofertada) cuando el tipo lleva la tasa de inflación esperada. Entonces, si la tasa es del $10 \%$ al año, un nuevo sol se podría intercambiar por S/.1,10 en el futuro.

Es real cuando a la tasa nominal se deduce la tasa de inflación esperada. En el ejemplo anterior, si el nivel de precios sube en igual porcentaje a la tasa de interés nominal 10\%, entonces tendremos una tasa de interés real igual a "cero". Esta tasa se ajusta teniendo en consideración los incrementos del nivel de precios.

c) Tasa fija y Tasa variable. Fija es cuando se establece desde el inicio y para todo el periodo de la operación. Se sustenta en la estabilidad del nivel general de precios.

Es variable porque, si bien se define desde el principio, se determina un mecanismo de ajuste en función de la variación de los precios, aplicable en cada periodo en que se divide el plazo de operación, (p. ej. semestral, mensual).

d) Tasa a rebatir. La que se aplica sobre el saldo del principal; o sea, que conforme se amortiza (pagos parciales), el monto del capital va tornándose menor y las tasa se irán aplicando sobre una base más reducida. Usualmente en los créditos que se van cancelando en base a cuotas periódicas.

e) Tasa interbancaria. Es aquella tasa pasiva promedio que las empresas bancarias y financieras se conceden entre sí, los llamados préstamos interbancarios. Constituyen un mecanismo importante, pues permite una circulación de liquidez entre las empresas del sistema y además, influye sobre las restantes tasas que se cobran o se pagan en determinadas plazas. 
f) Tasas en función de los plazos. Aplicable a las operaciones activas y pasivas. Es usual, por ejemplo en nuestro país como en otros, que los bancos ofrezcan variedad de tipos de interés: en colocaciones, se aprecian los créditos comerciales, créditos para Pymes, para consumo; y las tasas se aplican en rangos temporales: hasta 30 días, de 31 a 90 días, de 91 días a 180 días, de 181 días a 360 días y más de 360 días, etc. En todos los casos los criterios aplicables para determinar la tasa de interés en las operaciones activas son dos: uno en función del tiempo y otro el riesgo. En otras palabras, si el plazo es más corto, el riesgo será menor, por tanto, menor la tasa de interés, y viceversa.

g) Tasas en función de la moneda. Son las aplicables a operaciones en moneda nacional y en moneda extranjera.

\section{El pago de intereses para personas ajenas al sistema financiero}

Las personas ajenas al sistema financiero pueden pactar intereses, hasta el límite máximo señalado por el BCRP. Es decir, no pueden exceder los topes máximos establecidos por esta entidad, conforme así lo estipula el artículo $1243^{\circ}$ del Código Civil, que prescribe:

"La tasa máxima de interés compensatorio y moratorio es fijada por el Banco Central de Reserva del Perú.

Cualquier exceso sobre la tasa máxima da lugar a la devolución o a la imputación al capital, a voluntad del deudor"

Profundizando en el estudio del régimen legal de pago de intereses regulado en Código Civil, que hasta antes del 25 de abril de 1991 regía también al sistema financiero nacional, se puede señalar que cuando el Código Civil establece que la tasa máxima de interés convencional compensatorio o moratorio es fijada por el BCRP, ello quiere decir que las partes en un contrato pueden acordar libremente la tasa de interés compensatorio y moratorio, conforme al principio de autonomía privada de la voluntad de las partes, pero siempre dentro de los límites o topes señalados por la autoridad bancaria (BCRP). A partir de dichos topes se constituye la usura, que incluso se encuentra tipificada como delito en el Código Penal Peruano ${ }^{13}$.

13 Art. 214.-Usura

El que, con el fin de obtener una ventaja patrimonial, para sí o para otro, en la concesión de un crédito o en su otorgamiento, renovación, descuento o prórroga del plazo de pago, obliga o 
RODRÍGUEZ ${ }^{14}$ al referirse a la limitación legal para el cobro de intereses, y a sus consecuencias en cada sistema jurídico, anota que se trata de una "sanción civil para la usura, o cobro excesivo de intereses por el préstamo de un capital, que tanto toca con el problema de soberanía monetaria como con principios de moralidad, porque se considera que en la relación mutual el deudor es la parte débil y no puede dejarse abierta la posibilidad de que el acreedor señale a su arbitrio y en forma excesiva una tasa de interés que, por su elevado monto, pueda resultar una carga inequitativa para aquel".

Así, la finalidad perseguida al establecerse una limitación legal es evitar el abuso, el exceso y el cobro de intereses desproporcionados, usurarios, que torne a la relación jurídica en inequitativa e injusta, con lo cual se pretende salvaguardar los derechos del deudor en la consideración de que es la parte débil de la relación jurídica. En otras palabras, el derecho sale en defensa de los intereses de la parte más vulnerable de la relación contractual, de aquella parte con menor poder, de aquel de quien pueden aprovecharse ya sea por su fragilidad, por su necesidad, por su ignorancia o por su pobre condición económica.

En este sentido, el Código Civil ha establecido una serie de instituciones orientadas a defender patrimonialmente al deudor y a proporcionar reglas de equilibrio entre las partes que celebran un contrato, a fin de que no se permita que el contratante de mayor preponderancia pueda abusar o aprovecharse de aquel que, por distintas razones, está en situación desventajosa. Entre las instituciones que buscan tal finalidad, se pueden citar: El no abuso del derecho regulado en el artículo II del título preliminar; la nulidad del acto jurídico contrario a la ley y a las buenas costumbres señalada en el artículo $V$ del Título Preliminar, la excesiva onerosidad de la prestación contemplada en los artículos $1440^{\circ}$ a $1446^{\circ}$, la lesión regulada por los artículos $1447^{\circ}$ a $1456^{\circ}$; entre otros distintos dispositivos que son consecuencia de la aplicación del principio favor debitoris. En este orden de ideas, la doctrina Civil se pronuncia siempre a favor del equilibrio y la equidad en las relaciones económicas, consecuentemente ha señalado límites a la fijación de tasas de interés a fin de de evitar el cobro de intereses usurarios.

hace prometer pagar un interés superior al límite fijado por la Ley será reprimido con pena privativa de libertad no menor de uno ni mayor de tres años y con veinte a treinta días-multa. Si el agraviado es persona incapaz o se encuentra en estado de necesidad, la pena privativa de libertad será no menor de dos ni mayor de cuatro años.

14 RODRíGuez AZUERO, Sergio (2008). Contratos Bancarios. Su significación en América Latina. $4^{\circ}$ reimpresión de la $2^{\circ}$ ed., Colombia: LEGIS, p. 485. 
Bajo lo establecido por el artículo $1243^{\circ}$ del Código Civil, el BCRP, al amparo del artículo $51^{\circ}$ de su Ley Orgánica, ha emitido una serie de circulares cuya finalidad ha sido fijar los topes máximos a las tasas de interés, que actualmente se encuentran regulados en la Circular 021-2007-BCRP, vigente a partir del 01 de octubre de 2007, la misma que dejó sin efecto las circulares $\mathrm{N}^{\circ}$ 006-2003-EF/90 y $\mathrm{N}^{\circ}$ 007-2003-EF/90. De la revisión de estas disposiciones normativas, se puede resumir el siguiente tratamiento:

\section{A.- Para Operaciones en Moneda Nacional}

a) En el periodo comprendido entre abril de 1991 hasta el 30 de setiembre de 2007:

La tasa máxima de interés convencional compensatorio, dependerá del plazo de la operación.

Para operaciones de hasta 360 días, es equivalente a la Tasa Activa de Mercado Promedio Ponderado Efectiva en moneda nacional (TAMN).

Para créditos a plazo mayor a 360 y hasta 719 días es TAMN + 1; y para operaciones mayores a 720 días es TAMN +2 .

La Tasa máxima de interés convencional moratorio para el mismo periodo es $15 \%$ de la TAMN.

b) En el periodo que inicia el 1 de octubre del 2007 en adelante:

La tasa máxima de interés convencional compensatorio es equivalente a la tasa promedio del sistema financiero para créditos a la microempresa.

La tasa máxima de interés convencional moratorio para el mismo periodo es $15 \%$ de la tasa promedio del sistema financiero para créditos a la microempresa.

\section{B.- Para operaciones en Moneda Extranjera}

a) En el periodo comprendido entre abril de 1991 hasta el 30 de setiembre de 2007:

La tasa máxima de interés compensatorio y moratorio es equivalente a la Tasa Activa de Mercado Promedio Ponderado Efectiva en moneda Extranjera (TAMEX) independientemente del plazo de la operación. 
La Tasa máxima de interés convencional moratorio es equivalente al $20 \%$ de la TAMEX.

b) En el periodo que inicia el 1 de octubre del 2007 en adelante:

La tasa máxima de interés convencional compensatorio es equivalente a la tasa promedio del sistema financiero para créditos a la microempresa.

La tasa máxima de interés convencional moratorio para el mismo periodo es $20 \%$ de la tasa promedio del sistema financiero para créditos a la microempresa.

\section{El pago de intereses dentro del Sistema Financiero}

Las ESFN no están sujetas a limitación alguna para señalar tasas de interés, pues esta limitación ha sido proscrita a partir de abril de 1991, con la liberalización de la economía y con ello de las tasas de interés del sistema financiero. Conforme al artículo $14^{\circ}$ del Decreto Legislativo № 637 (hoy derogado), los bancos y demás empresas del sistema financiero pueden fijar libremente sus tasas de interés activas y pasivas. La misma libertad se reproduce en el artículo $17^{\circ}$ del derogado Decreto Legislativo $\mathrm{N}^{\circ} 770 \mathrm{y}$ también el artículo $9^{\circ}$ de la Ley $N^{\circ} 26702$, Ley General del Sistema Financiero y del Sistema de Seguros y Orgánica de la Superintendencia de Banca y Seguros - en adelante Ley General del Sistema Financiero-. Por tanto, las ESFN a partir de abril de 1991, no están sujetas a las tasas máximas fijadas por el BCRP15.

Esta regulación de las tasas de interés, se sustenta en la Doctrina que sostiene que la libre competencia en el mercado financiero es adecuada para determinar tasas de interés que mejor conviene a los actores económicos, eliminando así los topes a que se refiere el Código Civil. En este sentido, la circular $\mathrm{N}^{\circ}$ 021-2007-BCRP señala que, en las operaciones activas y pasivas de las ESFN, en cualquiera de sus modalidades, la tasa de interés convencional compensatorio y moratorio se determina por la libre competencia en el mercado financiero y es expresada en términos efectivos anuales, lo cual conlleva a una ausencia total del Estado en la aplicación de

15 Cfr. AVELINO SÁNCHEZ, Esteban (2006). Tasas de interés máximas contra la usura. Revista Quipucamayoc. Lima, Volumen 13, $\mathrm{N}^{\circ}$ 26. Consulta: 30 de enero de 2010, en http://sisbib.unmsm.edu.pe/bibvirtualdata/publicaciones/quipukamayoc/2006/segundo/ a11.pdf 
topes máximos; dejando al mercado financiero su autorregulación y autocontrol de las tasas de interés.

Es decir, las tasas de interés que las ESFN aplican a los créditos de consumo se encuentran exentas de limitación alguna, y son fijadas por la libre competencia en el mercado financiero; esto significa que cada Banco o Entidad Financiera señalará libremente las tasas de interés que cobran en los créditos de consumo que otorguen. Desde este punto de vista, las ESFN deberán ofrecer las tasas de interés competitivas a efecto de que los usuarios las prefieran, respecto de otras empresas competidoras.

CASTELLARES ${ }^{16}$ explica que la libre competencia es uno de los principios que anima y sustenta a la legislación bancaria y financiera, "pues se trata de lograr un sistema financiero competitivo, con lo que se logrará una banca profesional que preste una excelencia en sus servicios. La empresa que no esté en condiciones de prestar esa clase de servicios sucumbirá ante sus competidores que ofrecen lo mismo, más barato y mejor. No hay más diferencias, ni privilegios y menos monopolios para un determinado sector o inversionista. La banca practicada sea por inversionistas nacionales o extranjeros, públicos o privados, operan dentro de las mismas reglas de juego en igualdad de condiciones. Igualmente, el acceso al crédito del sistema financiero no se limita según la existencia o no de inversiones extranjeras en el prestatario (cliente) como era antes; todos los sujetos de crédito, incluyendo a los no residentes, son tratados por igual. Los residentes o nacionales no tienen ninguna ventaja frente a los extranjeros. Los bancos pueden colocar libremente en el exterior los recursos que capten en el país y viceversa. Las tasas de interés y las comisiones por los servicios financieros, se fijan de acuerdo a la libre competencia y al mercado. Cada empresa bancaria o de seguros fija sus tarifas libremente. Tales fuerzas del mercado no estarán más regidas por decreto de la autoridad de turno. La autoridad intervendrá solo cuando haya alguna distorsión de tales fuerzas económicas, pudiendo fijar no solo tasas máximas de los intereses activos o pasivos, sino inclusive tasas mínimas".

Como se advierte, según esta doctrina, la libre competencia en el mercado financiero se constituye en la razón para permitir que las ESFN establezcan tasas de intereses compensatorios y moratorios sin topes; pues se considera que será la libre competencia la que establecerá tasas de interés en equilibrio

16 Castellares Agullar, Rolando (1998). Banca y Seguros. Compendio Legislativo. T. I, TrujilloPerú: Normas Legales, p. 4. 
de acuerdo al mercado financiero; $\mathrm{y}$, como consecuencia de ello, considera apropiado prescindir del Estado, negándole toda facultad de intervención en el establecimiento de límites o topes a las tasas de interés (Salvo excepcionalmente, excepción que no se ha presentado hasta la fecha).

REBOLLEDO y SOTO17, han señalado que en un mercado competitivo las entidades crediticias no tienen la capacidad para fijar sus tasas de interés, por lo que en el equilibrio, la tasa de interés de mercado es igual a su costo marginal. Sin embargo - agrega -, la existencia de imperfecciones en el mercado conlleva a que la situación competitiva ideal diste, en mayor o menor medida, de las estructuras de mercado existentes, permitiendo a los oferentes fijar tasas de interés más elevadas y así, obtener ganancias extraordinarias.

Más adelante veremos cómo la realidad ha rebatido la idea de un "mercado ideal", sustento teórico para que se permita el cobro de intereses sin topes por las ESFN.

\section{El crédito de consumo}

\subsection{Definición}

Desde el punto de vista económico, el crédito es entendido como la utilización de fondos de otra persona a cambio de la promesa de devolverlos (normalmente con intereses) en fecha posterior. En realidad, la razón de ser del crédito son precisamente los intereses, es decir la renta por el uso del dinero prestado, el beneficio económico del prestamista. Sin esta ventaja, el crédito tal como lo conocemos actualmente, no existiría ${ }^{18}$.

El contrato de crédito deriva del contrato matriz denominado mutuo o préstamo. Para RODRÍGUEZ los créditos de consumo incluyen "préstamos cambiarios, créditos en cuenta, créditos para el consumo o la inversión, créditos a simple firma o con garantía, etc. modalidades todas ellas que, si bien pueden revestir una individualidad desde el punto de vista técnico, corresponden al mismo sustento conceptual, jurídicamente considerados: la celebración de un contrato de Mutuo. Esto es, que para todas las

17 ReBOlledo ABANTO, Paúl y Robert SOTO CHÁVEZ. Estructura del mercado de créditos y tasas de interés: una aproximación al segmento de las microfinanzas. Perú: BCRP, 2004, Consulta: 30 de enero de 2009, en http://www.bcrp/docs/publicaciones/documentos.detrabajo/2004/documento-trabajo-7-2004.pdf

18 GutiÉRrez CAMACHO, Walter y Nelwin CASTRO (2007). Definición de Mutuo. En AA.VV. Código Civil Comentado. Tomo VIII, Lima: Gaceta Jurídica, p. 443. 
modalidades los principios generales de entrega, restitución y plazo son aplicables indistintamente ${ }^{19 \prime}$. Al respecto, el Código Civil Peruano en su artículo $1648^{\circ}$ señala que el contrato de mutuo "es aquel por el cual el mutuante se obliga a entregar al mutuatario una determinada cantidad de dinero o de bienes consumibles, a cambio que se le devuelvan otros de la misma especie, calidad o cantidad"20.

Dentro del crédito al consumo, ha asumido gran trascendencia en los últimos tiempos el uso de las tarjetas de crédito, cuya facilidad y flexibilidad de uso suma gran cantidad de usuarios de este servicio. Como anota GHERSI21 "a través de la tarjeta de crédito, el consumidor simplifica notablemente sus operaciones, debido a la sustitución del dinero efectivo, pero principalmente tiene a su alcance un importante instrumento de crédito, toda vez que le es posible diferir el cumplimiento de sus obligaciones dinerarias mediante su presentación, y sin ser necesaria la previa provisión de fondos a la entidad que asume la deuda".

Consecuentemente, el crédito de consumo, es aquel por el cual un proveedor, normalmente una empresa del sistema financiero, transfiere un monto dinerario a favor del usuario, para que pueda obtener bienes o servicios destinados a su uso personal o familiar, cualquiera sea la técnica jurídica utilizada para realizar tal crédito.

\subsection{Principios que sustentan la tutela de los usuarios de créditos de consumo}

Un principio "abriga la idea de base, origen o razón fundamental o primera de una materia y sirve de punto de referencia para ulteriores desenvolvimientos. Esta característica de idea fundante - que, naturalmente, requiere ser precisada - confiere al principio una jerarquía y un peso primordial, pero debe conjugarse con el aspecto un tanto más dinámico de la

19 Ver RODRíGUEZ AZUERO, Sergio. Op. cit., p. 477.

20 Esta definición, a decir de MFZA, es antitécnica, al estar redactada en forma incorrecta y contener un pleonasmo, por tanto propone la siguiente definición: “El mutuo es el contrato por el cual el mutuante se obliga a transferir la propiedad de bienes fungibles al mutuatario, correspondiéndole a este restituir en el plazo pactado o establecido en la ley. Cfr. MFZA FINOCHETTI, Roberto. El contrato de mutuo. Normas legales. Legislación y doctrina, $\mathrm{N}^{\mathrm{o}} 275$, Trujillo-Perú: Normas Legales, 1998, p. A49.

21 GHERSI, Carlos Alberto. Contratos civiles y comerciales. T.II. $4^{\circ}$ Ed. ASTREA, Buenos Aires, 1998, p. 237. 
orientación, del servir de 'rosa de los vientos' en el difícil camino de la justicia"22.

Con la dación del Código de Protección y Defensa del Consumidor se han recogido de manera expresa una serie de principios que orientan la labor de tutela de los consumidores y usuarios, los cuales han sido estudiados por la doctrina. Para los fines del presente trabajo haremos referencia, básicamente, a cuatro de los principios enunciados en el artículo V del Título Preliminar del Código del Código de Protección y Defensa del Consumidor, que nos servirán para poder dar respuesta a nuestra interrogante. Entre estos tenemos:

Principio proconsumidor: Se trata de un enunciado de carácter general que orienta toda la regulación referida a la protección de los consumidores y usuarios. En virtud de este principio se señala que, en cualquier campo de su actuación, el Estado ejerce una acción tuitiva a favor de los consumidores, conforme así lo prescribe el Código de Protección y Defensa del Consumidor.

Ante la pregunta: ¿Por qué tutelar al consumidor (o usuario)? $\mathrm{ALPA}^{23}$ nos responde y afirma que "hoy, en una sociedad pluralista en la que los derechos civiles están en fase de expansión, y los derechos de los trabajadores adecuadamente garantizados, uno de los límites que se pueden añadir al gobierno de la sociedad por parte de las reglas del mercado es aquel constituido por la tutela de los intereses de los destinatarios de los productos y servicios. Por consiguiente, no es una instancia hedonista aquella que sostiene el andamiaje de los derechos de los consumidores, cuando más bien la coordinación y la adaptación de intereses en conflicto y, por lo tanto, susceptibles de mediación. Esta última no se puede obtener de manera, por así decir, natural, dejando liberar y prosperar solamente las fuerzas económicas del mercado, porque los portadores de aquellos intereses están en una situación objetiva diversificada, con una desigual distribución del poder, de manera que una de las tareas de las instituciones consiste precisamente en introducir reglas de equilibrios de los intereses en juego. Las reglas en su momento

22 REZZÓNICO, Juan. Principios fundamentales de los contratos. ASTREA, Buenos Aires, 1999, p.10.

23 ALPA, Guido (2004). Derecho del consumidor. Traducción de Espinoza Espinoza, Juan. Lima: Gaceta Jurídica, p. 43. 
adecúan el 'peso' de los diversos intereses, teniendo en cuenta los diferentes sectores".

Principio de transparencia: El Código de Protección y Defensa del Consumidor, recogiendo este principio, señala que "en la actuación en el mercado, los proveedores generan una plena accesibilidad a la información a los consumidores acerca de los productos y servicios que ofrecen. (...) La información brindada debe ser veraz y apropiada."

Según HENRÍQUEZ24 este principio "busca una relación más próxima y adecuada entre el proveedor y el consumidor. (...) Permite un enfoque directo concerniente a la verdadera intención de cada uno de ellos, en el sentido de que, de forma pura se instaure a plena satisfacción en la atención de los fines objetivados en la contratación: la provisión y la recepción del producto o servicio en el sentido de pleno conocimiento de condiciones." Este mismo autor agrega que "transparencia es clareza, es información adecuada y oportuna sobre los temas relevantes de la futura relación contractual. (...) El Principio de transparencia impone al proveedor el deber de la efectiva y directa información sobre todas las condiciones del negocio a ser realizado, comprendiendo tanto la oferta como el texto del propio compromiso cuando es escrito o la divulgación amplia de las condiciones cuando, por corresponder a un pequeño negocio, fuera verbal".

En materia de productos o servicios financieros el principio de transparencia ha sido regulado por el artículo $82^{\circ}$ del Código Protección y Defensa del Consumidor y desarrollado ampliamente por la Ley $\mathrm{N}^{\circ}$ 28587, Ley Complementaria de Protección al Consumidor en Materia de Servicios Financieros.

Principio de corrección de la asimetría. Conforme al Código de Protección y defensa del consumidor: "Las normas de protección al consumidor buscan corregir las distorsiones o malas prácticas generadas por la asimetría informativa o la situación de desequilibrio que se presente entre los proveedores y consumidores, sea en la contratación o en cualquier otra situación relevante, que coloquen a los segundos en una situación de desventaja respecto a los primeros al momento de actuar en el mercado. "

24 HeNRíQUEZ CRUZ, Guillermo (2002). La relación contractual consumidor-empresa bancaria o financiera en Brasil. Revista Bibliotecal. Año 3, N 5, Lima: Colegio de Abogados de Lima, p. 203 204. 
$\mathrm{Al}$ respecto, MERINO25 señala que "el fundamento de la tutela del consumidor ha sido desarrollado desde distintos puntos de vista, el primero y más difundido es la asimetría informativa que existiría entre proveedor y consumidor, el segundo es la asimetría económica, y el tercero la asimetría de negociación." Indica que "la asimetría de la información se basa en una constatación objetiva de los intercambios del mercado. (...) en los intercambios económicos del mercado el proveedor ostenta mucha más información que el adquirente, información relativa al bien, a las circunstancias, al contrato, la misma que lo pondría en una situación de superioridad frente al consumidor." Además, agrega que, "un fundamento importante de la tutela del consumidor es (y debe ser también en el plano normativo) la asimetría en la negociación. El hecho de que en el consumidor no pueda intervenir en el contenido del contrato es fundamento suficiente para que tenga una especial protección." Finalmente anota que "la asimetría informativa y la asimetría económica - en la mayoría de casos - no sería más que los fundamentos de la asimetría de negociación, dado que la asimetría de la información, junto con las condiciones personales y económicas, pueden conducir a un poder de negociación inequitativo".

Este principio se relaciona con el de "equidad de las prestaciones", que "se caracteriza como el respeto al equilibrio entre deberes y derechos con la finalidad de encontrar la justicia contractual. Significa vedar en la utilización, por parte del proveedor, de clausulas que aseguren ventajas desproporcionadas, (...) resultando también en conflicto con la buena fe que debe existir en torno de cualquier contrato, principalmente el de consumo" ${ }^{\prime 26}$.

REZZÓNICO ${ }^{27}$ lo llama principio de equivalencia, y afirma que este "procura que ninguno de los contratantes quede en situación de desmedro patrimonial frente al otro que sí aprovecha en mayor medida las ventajas de la relación, aunque de ninguna manera persigue una equivalencia matemática".

25 MERINO ACUÑA, Roger (2007). Las asimetrías entre proveedor y consumidor en el marco de la bifurcación de la autonomía contractual ¿de la parte al status? Revista Jurídica del Perú, $\mathrm{N}^{\circ}$ 77, Lima: Gaceta jurídica, p. 255-257.

26 HENRÍQUEZCRUZ, Guillermo. Op. cit., p. 210-211.

27 REZZÓNICO, Juan. Op. cit., p. 283. 
Principio de buena fe: La buena fe "constituye un concepto que excede ampliamente el marco jurídico, tiene un profundo contenido ético que importa un obrar conforme a la honestidad, la lealtad y la previsibilidad. La conducta ajustada a este principio, lógicamente, genera la tan ansiada confianza, que constituye el 'mejor clima' para el desarrollo de negocios jurídicos y es la base de la seguridad jurídica, valor tan arduamente perseguido en todos los tiempos"28.

Se trata de un principio que irradia todo el Derecho, "en la actualidad, el concepto de buena fe no significa, simplemente, una actitud pasiva, no actuar de mala fe, importa una conducta activa, de cooperación con la otra parte, a los efectos que el contrato tenga para ambas partes, el mejor resultado posible, los mayores beneficios $y$, consecuentemente, los menores 'costos prestacionales', que no siempre resultan económicos, sino que también pueden ser psicológicos o emocionales. Esto establece un estándar de conducta social, basado en la solidaridad"29.

Para DE LA PUENTE Y LAVALLE" "La buena fe es la base de la contratación: sin ella el vínculo jurídico no puede constituirse, sino aparentemente, ya que la ley fulmina la ineficacia de los contratos en que interviene dolo o fraude. Debe presidir también la ejecución del contrato o sea el cumplimiento de las obligaciones por él generadas. La buena fe consiste aquí en que cada interesado tenga en cuenta no solo su propio interés, sino el de la contraparte, pues ambos han servido como motivo determinante para el ajuste del convenio. La buena fe, en la ejecución de los contratos es antitética de toda especie de dolo o fraude en el cumplimiento de la obligación jurídica".

REZZÓNICO ${ }^{31}$ señala que la buena fe "es una expresión que puede adquirir distintos significados, dependiendo del círculo social en que sea utilizada la palabra. Por ello, en el lenguaje común sirve para designar una particular condición del espíritu de quien obra,

28 ESTIGARRIBIA BIEBER, María (2005). La buena fe. Implicaciones actuales en las relaciones negociales. En AlBAN, Jorge y César CARRANZA (Comp.) Estudios de Derecho Privado contemporáneo. Contratos - Teoría General, contratación predispuesta, de consumo y financiera, Trujillo - Perú: Industria Gráfica Libertad SAC, p. 63.

29 Ibídem, p. 64.

30 De la Puente y LaVAlLe, Manuel (2000). La fuerza de la buena fe. En Alterini, Aníbal; De LOS Mozos, José y Carlos Soto, (Comp.). Contratación contemporánea. Teoría y Principios, Bogotá: Palestra, p. 279.

31 REZZÓNICO, Juan. Op. cit., p. 482. 
mientras que, en otro ámbito, verifica condiciones como la honestidad, la probidad y la lealtad del comportamiento."

Por su parte, el Código de Protección y Defensa del Consumidor prescribe que "En la actuación del mercado y en el ámbito de vigencia del presente código, los consumidores, los proveedores, las asociaciones de consumidores y sus representantes, deben guiar su conducta acorde con el principio de la buena fe, de confianza y lealtad entre las partes. "

\section{Tasas de interés, transparencia y tutela de los usuarios de créditos de consumo}

El siguiente cuadro presenta de modo referencial las tasas de interés promedio más altas que han sido pactadas por ESFN para créditos de consumo durante los dos primeros meses de 2016, mostrando una comparación por cada tipo de empresas en relación con la tasa máxima establecida por el BCRP para personas ajenas al sistema financiero que, como se ha visto, corresponde a la tasa promedio del sistema financiero para créditos a la microempresa ${ }^{32}$.

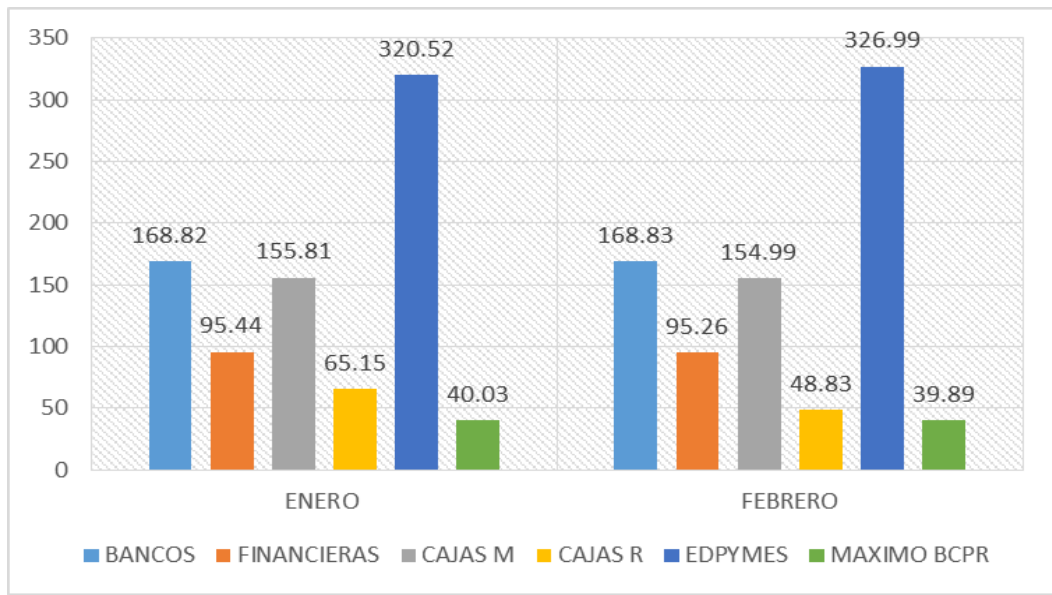

Gráfico № 01: Gráfico comparativo entre las tasas de interés promedio más elevadas cobradas por las esfn para créditos de consumo y las tasas máximas establecidas por el bcr durante eses del año 2016 (moneda nacional) Fuente: portal webSBS

Elaboración: el autor.

32 Superintendencia de Banca, Seguros y AFP. Tasas de interés promedio, en http://www.sbs.gob.pe/principal/categoria/tasa-de-interes-promedio/154/c-154, consulta: 29 de febrero de 2016. 
El gráfico $\mathrm{N}^{\circ} 01$ pone en evidencia que aún en un sistema de "libre competencia", en el cual existen empresas competidoras con tasas menores, se viene aplicando excesivas tasas de interés. Se colige así, que la doctrina que ha servido de justificación para permitir que las ESFN fijen libremente y sin topes sus tasas de interés, dejando al mercado su autorregulación (por tanto sin intervención alguna del Estado en la determinación de topes máximos), no ha pasado del nivel teórico, pues ha sido desvirtuada en la realidad, en la cual no se ha visto reflejado aquellos "beneficios" de la libre competencia, observándose una diversificación en las tasa de interés y, lo que es grave, la existencia de tasas de interés excesivas y desproporcionadas que no es acorde con un sistema de libre competencia. Así, mientras las tasas máximas establecidas por el BCRP durante los dos primeros meses del año 2016 (enero y febrero) ha oscilado entre $40.3 \%$ y 39.89\%, en el caso de los bancos la tasa promedio más alta ha sido de $168.82 \%$, en caso de las financieras de 95.44, para las cajas municipales las tasas promedio más altas han llegado a $155.81 \%$, las cajas rurales han mostrado tasa promedios que han llegado a $65.15 \%$ y las tasas promedios más elevadas se presentan en el caso de las EDPYMES que han mostrados tasa promedios que han llegado hasta $326.99 \% 33$.

Bajo este contexto, se puede afirmar que a la fecha subsisten entidades del sistema financiero nacional que pactan en sus contratos tasas de interés desproporcionadas en relación a las tasas promedios del mismo sistema financiero. Estos intereses así pactados sin duda se los puede calificar de "usurarios", en el sentido amplio de la palabra, pues como anotan OSTERLING y CASTILLO ${ }^{34}$, citando a Manuel Albaladejo, el interés usurario "es aquel que es notablemente superior al normal y manifiestamente desproporcionado con las circunstancias del caso". Igualmente, los mismos autores citando a Dario Corgatelli refieren que "la usura es sinónimo de alto interés, interés odioso, desproporcionado, excesivo en el precio de los prestamos de dinero que el prestamista cobre, exija o se haga dar o prometer por su dinero"135. Es decir, las tasas de interés observadas son excesivas no solo porque son superiores a las tasas máximas fijadas por el BCRP, sino también porque no son ni cercanas a las tasas

33 Debe precisarse que las tasas de interés promedio del sistema financiero se calculan sobre la base de la información reportada por las empresas del sistema financiero a través del Reporte No6. Las tasas de interés tienen carácter referencial. Cfr. en: http://www.sbs.gob.pe/principal/categoria/tasa-de-interes-promedio/154/c-154

34 Citado por OsterLING PARODI, Felipe y CASTILLOFREYRE, Mario. Op. cit. p. 502.

35 Ídem. 
promedio del sistema financiero, pues de fijan sin considerar el análisis de los riesgos de la operación crediticia; es decir, son fijadas, a todas luces, de modo arbitrario y con el fin de obtener una ventaja excesiva.

Entonces, cabe interrogarnos: ¿Cómo se explica la existencia de estas tasas de interés excesivas, cuando en teoría deberían ser fijadas por una sana competencia entre las entidades financieras? Se explica por la ausencia de una real competencia en el mercado financiero, lo cual se debe básicamente a problemas de falta de información adecuada y veraz a favor de los consumidores y usuarios; fenómeno al que los economistas denominan "Falla del mercado".

CORTEZ $^{36}$ ha resaltado que, "en un mercado ideal de competencia perfecta, es un requisito indispensable que los agentes tengan información sobre todas las condiciones de precios o calidades que afecten a los intercambios sin coste alguno. El conocimiento pleno de las condiciones generales del mercado implica ausencia de incertidumbre. Desde un análisis estrictamente dogmático podríamos asegurar que en un contexto de competencia perfecta se aseguraría cualquier inconveniente de elección por parte de los consumidores. La situación se presenta complicada cuando asumimos que este discurso teórico no se presente como tal en la realidad concurrencial en la que la asimetría de la información es el común denominador en las relaciones comerciales actuales, lo que ha originado la necesidad de establecer todo un sistema normativo orientado a corregir las fallas que el mercado en su cotidianeidad presenta".

Por tanto, la doctrina que inspira a la Ley General del Sistema Financiero y que pretende que la libre competencia cumpla la función de hacer que las tasas de interés se fijen en el justo valor que le otorga el mercado (orientándolas a disminuir $\mathrm{y}$, de este modo, contribuir a lograr mejores servicios), tiene como presupuesto un mercado de competencia perfecta, que evidentemente, no existe en nuestro país. Así, en el ámbito de la realidad se aprecia que las ESFN no presentan tasas competitivas, pues mantienen elevadas y desalentadoras tasas de interés (como se aprecia en el gráfico $\mathrm{N}^{\circ}$ 01), no obstante lo cual siguen operando y manteniéndolas sin mayor problema.

36 CORTEZ TATAJE, Juan (2009). El problema de la información asimétrica y la razonabilidad de la intervención estatal en el Derecho de los Consumidores. Revista Jurídica del Perú, № 95, Gaceta Jurídica, Lima, p. 488. 
En este sentido, a pesar de que la legislación ha desarrollado una amplia normatividad a fin de cimentar el principio de Transparencia en el sistema financiero peruano, la realidad demuestra que dicho principio está lejos de consolidarse debido básicamente a las asimetrías existentes en este ámbito de la contratación.

Se ha visto que la transparencia en el sistema financiero es principio orientado a la protección de los usuarios, que obliga a las ESFN a difundir adecuadamente las tasas de interés que aplican a sus operaciones de crédito, ello en la lógica de que el suministrar la información necesaria al usuario constituye una garantía para que el mercado funcione correctamente. Sin embargo, los problemas de desinformación son comunes y reiterativos, lo que favorece que los usuarios celebren créditos de consumo sin el conocimiento suficiente que les permita decidir en base a una voluntad libre y sin vicios, pues si bien la mayoría de entidades financieras cuentan con paneles informativos de las tasas de interés y comisiones que cobran, dichos paneles se ubican en lugares poco visibles, no son claros ni entendibles para las personas de conocimiento promedio.

Ello es palpable cuando se aprecian estadísticas elaboradas por el Instituto de Defensa de la Competencia (INDECOPI) QUE en el último Reporte Estadístico publicado en su portal web ${ }^{37}$, correspondiente al mes de abril de 2015, se constata lo siguiente:

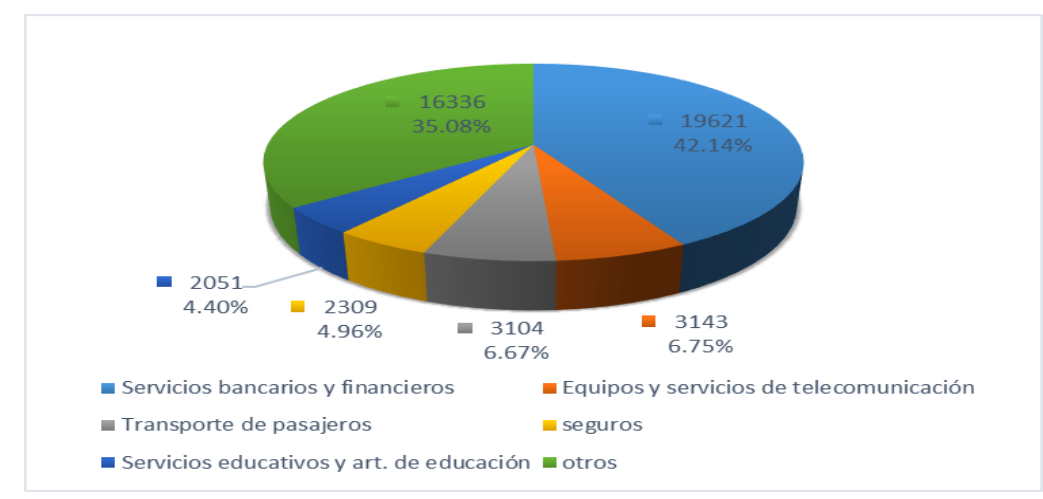

Gráfico N 02: Reclamos recibidos ante indecopi a nivel nacional según actividad económica (mayo 2014 - abril 2015). Fuente: Servicio de Atención al Ciudadano (Sac) del INDECOPI.

Elaboración: el autor.

37 INDECOPI (2015). Reporte de estadísticas Institucionales. Año 15, $\mathrm{N}^{\circ} 147$, en https://www.indecopi.gob.pe/documents/20182/143803/Abril2015.pdf, consulta: 22 de enero de 2016. 
En el precitado gráfico advertimos la incidencia de reclamos presentados ante esta entidad pública, durante el periodo comprendido entre los meses de Mayo 2014 a Abril 2015, constatándose que de un total de 46564 reclamos presentados en el Sistema de Atención al Ciudadano de la mencionada Institución, 19621 corresponden a servicios bancarios y financieros, esto es, el $42,14 \%$ del total de los reclamos a nivel nacional corresponde a los mencionados servicios. Es decir, los servicios bancarios y financieros son los que tiene la mayor incidencia de reclamos por parte de los usuarios; ampliamente superior a la cantidad de reclamos respecto de las demás actividades económicas. Se deduce, por tanto, el mercado de créditos de consumo, no viene funcionando como teóricamente se espera, pues presenta fallas como la falta de transparencia.

En la realidad práctica, la tan esperada transparencia en el mercado financiero no se ha materializado, pues el común denominador es la desinformación de los usuarios respecto de las condiciones en las que contratan los créditos de consumo. Y ello es así, debido a que "la 'sociedad de consumo' en la que estamos inmersos desde hace algunas décadas coloca a los consumidores en una situación de debilidad y vulnerabilidad estructural en sus relaciones con los proveedores de bienes y servicios. Relaciones que, en muchos casos, se encaminan en un sendero de conculcación de derechos, incumplimientos, daños materiales e inmateriales, abusos y frustraciones, especialmente entre los consumidores de sectores menos favorecidos" ${ }^{\prime 38}$.

Por tanto, creemos que, en el ámbito de los contratos de consumo, la libre competencia en el mercado financiero peruano no garantiza tasas de interés justas, que mantengan el equilibrio en las prestaciones que debe existir en toda relación comercial, debido a las características especiales de las relaciones de consumo, como explicaremos a continuación.

\section{Libertad para fijar tasas de interés y tutela de los usuarios de créditos de consumo}

Existe un marco constitucional de tutela del usuario y de sus derechos, que proviene desde el artículo $1^{\circ}$ de la Constitución Política del Estado, que

38 Sebastián BAROCHelli, Sergio (s.a.). El concepto de Consumidor en el nuevo Código Civoil y Comercial, en http://www.nuevocodigocivil.com/wp-content/uploads/2015/08/Elconcepto-de-consumidor-en-el-nuevo-CCyC-por-Barocelli1.pdf, consulta: 22 de enero de 2016. 
establece que "la defensa de la persona y el respeto de su dignidad son el fin supremo de la sociedad y del Estado"; además el artículo $65^{\circ}$ expresamente dispone que "El Estado defiende el interés de los consumidores y usuarios. Para tal efecto garantiza el derecho a la información sobre los bienes y servicios que se encuentran a su disposición en el mercado. Asimismo vela, en particular, por la salud y la seguridad de la población ${ }^{11}$; disposiciones que han sido desarrolladas por la legislación contenida en el Código de Defensa y Protección del Consumidor y otras normas a que se han hecho referencia en el presente trabajo.

Pese a este marco regulatorio que otorga a los consumidores y usuarios un régimen de tutela y un catalogo de derechos, que provienen desde la más alta jerarquía normativa, y que se sustenta, como hemos visto, en el desarrollo doctrinario del derecho civil y de la doctrina de los derechos de los consumidores y usuarios; el artículo $9^{\circ}$ de la Ley General del Sistema Financiero (que nace de la Doctrina de la Liberalización de la Banca y se basa en la consagración de la libre competencia en el mercado), considera que las entidades del sistema financiero nacional pueden cobrar intereses compensatorios y moratorios de manera ilimitada y sin topes, con la única condición de "informar adecuadamente a los usuarios".

Como se ha señalado, en toda relación de consumo existen evidentes asimetrías, como la económica, la informativa y de negociación. Estas asimetrías son más evidentes en el ámbito de los contratos de créditos de consumo, donde los usuarios contratan en situación de notable desventaja, pues no cuentan con la información ni el conocimiento de las reales condiciones en las que contratan, incluyendo las tasas de interés que se aplican a sus créditos; y, en todo caso, aun conociendo con certeza estas condiciones, no pueden negociarlas por tratarse de contratos por adhesión.

La protección al consumidor y usuario, en este ámbito de contratación, no solo debe basarse en la obligación de transparencia o información, pues como se ha señalado "el derecho a la información no es suficiente para equilibrar las relaciones de consumo, pues el hecho de que yo esté informado del abuso o de la injusticia no la impide, ni la obstaculiza. No basta 'informar', es necesario impedir las injusticias, y para esto el derecho está obligado a intervenir y valorar negativamente las acciones o pactos que considere intolerables para la vida en relación o para la dignidad del hombre. Hoy el centro del sistema jurídico lo constituye el ser humano"39.

39 GONZALES BARRÓN, Günther (2010). El mito del consumidor razonable. Revista Actualidad Jurídica. Tomo N²02, Gaceta Jurídica, Lima, p. 21. 
Bajo este contexto, la libertad de las ESFN para fijar tasas de interés sin topes, genera que las relaciones jurídicas derivadas de los contratos de consumo, se torne en inequitativas, debido a las excesivas tasas de interés existentes; lo cual no promueve, en modo alguno, la corrección de las asimetrías existentes en este ámbito de contratación, pues no toma en cuenta las condiciones desventajosas en que contratan los usuarios; quienes en la práctica no toman pleno conocimiento de las condiciones de la contratación ni de las tasas de interés aplicables y por ende son fácilmente burlados.

Así, el régimen legal contenido en el artículo $9^{\circ}$ de la Ley General del Sistema Financiero, que permite se celebren contratos de créditos de consumo con elevadas tasas de interés, sin duda alguna, contraviene el principio de corrección de la asimetría, pues legitima un tratamiento inequitativo en las prestaciones nacidas de estos contratos. Este principio está relacionado con el equilibrio y la equidad en las prestaciones, tiene que ver con un sentido de justicia en las relaciones de consumo.

Entonces, lejos de promover una conducta ajustada a las buenas prácticas comerciales, el artículo $9^{\circ}$ de la Ley General del Sistema Financiero propicia que la ESFN puedan aprovecharse de su posición preferente; atentando contra el principio de buena fe en la contratación y legitimando que estas empresas muestren un comportamiento contrario a las reglas de la corrección, la confianza y lealtad.

Resulta necesario, por lo señalado, que el Derecho tome cartas en el asunto, pues pese a que a nivel normativo existe una amplia regulación orientada a dar cumplimiento a la transparencia en el sistema financiero, con lo cual se pretende que el usuario cuente con toda la información relevante para que pueda realizar una elección acorde con lo que le conviene; sin embargo, las condiciones concretas de disparidad contractual y problemas de desinformación en el mercado financiero, impide que esta finalidad se cumpla íntegramente. Es decir, el Derecho debe tener presente la realidad insoslayable, que evidencia la disparidad y abuso por parte de las ESFN en la contratación de créditos de consumo; consecuentemente, la tutela del usuario de créditos de consumo debe ir más allá que el brindarle información a los usuarios, para ser una tutela real, que genere un ambiente de confianza, corrija las asimetrías evidentes entre las partes y logre optimizar la transparencia y buena fe en las relaciones jurídicas derivadas de estos contratos. 
En este sentido, el Estado debe brindar una tutela orientada a evitar que los usuarios sean víctimas de tratamientos perjudiciales; por cuanto, detrás de cada usuario o consumidor está un ser humano, que cuenta con dignidad y merece respeto a su condición de persona. Es decir, conforme acota ALPA ${ }^{40}$ : "el mercado no puede ser dejado a sí mismo: la self regulation no da garantías suficientes para la tutela de todos los intereses involucrados en las singulares situaciones, también aquellos que excluyen la 'falla de mercado', que proponen el libre intercambio sin vínculos, lazos y ataduras, se han dado cuenta que algunas reglas de base deben ser mantenidas, y que algunos controles deben ser conservados".

Por ello, podemos afirmar que la facultad de las ESFN para fijar libremente tasas de interés sin topes, bajo el contexto del mercado financiero peruano que se ha explicado, atenta contra la tutela de los usuarios y contra sus derechos, además contra la dignidad de la persona del usuario, resultando necesario realizar un replanteamiento a la luz del Derecho y de los principio generales que se han estudiado, a fin de poder favorecer objetivos, ahora sí, como el desarrollo económico equilibrado tanto de los usuarios y del sector financiero, en un ambiente de justicia donde exista la mayor equivalencia y equilibro en las prestaciones derivadas de los contratos de créditos de consumo.

Existe pues, un fundamento de connotación superior para permitir al Estado intervenir en el sistema financiero que tiene que ver con valores como la solidaridad, la realización del bien común, el logro del bienestar general. "Aun dentro de la dogmática del radicalismo liberal se admite que el Estado está llamado a tutelar el buen suceso de la organización social, a partir del respeto de los intereses generales, para lo cual ordena las conductas ciudadanas a través de un sistema jurídico del cual las normas imperativas o de orden público se encargan de restringir la libre iniciativa en aras de la realización del bien común" 41 .

Escapa al objeto del presente trabajo desarrollar los fundamentos para una adecuada intervención estatal en la fijación de topes de las tasas de interés, tarea pendiente sin duda; sin embargo, debemos precisar que no se promueve que el Estado imponga las tasas de interés sino solamente señale límites a las mismas, dentro de un marco de libertad contractual y respeto de

$40 \quad$ ALPA, Guido. Op. cit.p. 36.

41 MARTíNEZ NEYRA, Néstor (1994). Sistemas Financieros. Derecho financiero comparado. Biblioteca Felabán, Bogotá, p. 231. 
la autonomía privada, principios rectores y fundamentales que orientan la contratación civil, comercial y financiera. Es decir, se busca que la legislación reconozca una realidad irrefutable de desigualdad de información, económica y de negociación existente en el campo de la contratación de créditos de consumo, por lo que la función del Estado, en este contexto, es velar por restituir el equilibrio y la equidad en las relaciones contractuales para evitar el abuso y aprovechamiento de la parte más fuerte y proteger a los usuarios de créditos de consumo.

En todo caso, por ahora queremos terminar el presente trabajo, haciendo referencia a las expresiones de CÁRDENAS y MARTÍNEZ ${ }^{42}$, cuando señalan que "el contrato es un medio de cooperación social que está al servicio del hombre como un vehículo integrador, armonizador, cooperador de las relaciones sociales (...),y no como un mecanismo de explotación, de abuso de una parte sobre otra...para llegar a un tratamiento socialmente justo, dentro de un perfil humanista y solidario del ordenamiento jurídico". Con dicho propósito esperamos contribuir en algo.

\section{Conclusiones}

a) La Libre competencia en el Sistema Financiero, no garantiza el equilibrio de las prestaciones, menos la justicia en las relaciones de consumo, al evidenciarse altas tasas de interés aplicadas a créditos de consumo, siendo estas desproporcionadas en relación con las tasas promedio del propio sistema financiero y las tasas máximas establecidas por el Banco Central de Reserva del Perú, lo que pone de manifiesto un aprovechamiento de esta facultad por parte de algunas ESFN para señalar excesivas tasas de interés, perjudicando a los usuarios de créditos de consumo.

b) La Libertad para fijar tasas de interés regulada en el artículo $9^{\circ}$ de la Ley 26702 - Ley General del Sistema Financiero y del Sistema de Seguros y Orgánica de la Superintendencia de Banca y Seguros contraviene la tutela jurídica de los usuarios de créditos de consumo, pues no contribuye a corregir las asimetrías existentes en este ámbito de la contratación, y vulnera los principios de equilibrio de las prestaciones y buena fe, por lo que es necesario que el Estado establezca topes a las tasas de interés pactadas por ESFN, a fin de

42 Citados por ARIAS-SCHREIBER PEZET, Max (1990). La defensa patrimonial del deudor en el Código Civil Peruano de 1984. En AA.VV. "Tendencias Actuales y perspectivas del Derecho Privado y el Sistema Jurídico Latinoamericano", Cultural Cuzco, Lima, p. 265. 
tutelar de manera efectiva y real a los usuarios de créditos de consumo.

\section{Bibliografia}

ALPA, Guido. Derecho del consumidor. Espinoza Espinoza, Juan. (Traductor), Lima: Gaceta Jurídica, 2004.

AVELINO SÁNCHEZ, Esteban. "Tasas de interés máximas contra la usura". Revista Quipucamayoc. Lima, Volumen 13, N²6, 2006. Consulta: 30 de enero de 2010, en http://sisbib.unmsm.edu.pe/bibvirtualdata/publicaciones/quipukama yoc/2006/segundo/a11.pdf

ARIAS-SCHREIBER PEZET, Max. "La defensa patrimonial del deudor en el Código Civil Peruano de 1984". En AA.VV. Tendencias Actuales y perspectivas del Derecho Privado y el Sistema Jurídico Latinoamericano (pp. 257-265), Lima: Cultural Cuzco, 1990.

CÁRDENASQUIRÓS, Carlos. "El pago de intereses en el Código Civil de 1984". En AA.VV. Libro Homenaje a Rómulo E. Lanatta Guilhem (pp. 69-98). Lima: Cultural Cuzco, 1986.

CAstellares Agullar, Rolando. Banca y Seguros. Compendio Legislativo. T.I, Trujillo-Perú: Normas Legales, 1998.

CORTEZ TATAJE, Juan. "El problema de la información asimétrica y la razonabilidad de la intervención estatal en el derecho de los consumidores". Revista Jurídica del Perú (pp. 487-492), № 95, Lima: Gaceta Jurídica, 2009.

De la PuENTE y LaVAlle, Manuel. "La fuerza de la buena fe". En Alterini, Aníbal; De los Mozos, José; Soto, Carlos (Comp.). Contratación contemporánea. Teoría y Principios (pp. 273-285). Bogotá: Palestra, 2000.

DíAZ SILVA, Nathalie. "Las tasas de interés aplicables a las operaciones no financieras ¿Cómo se regulan los intereses en el Perú?" Revista Actualidad Jurídica (pp.55-58). № 136, Lima: Actualidad Jurídica, 2005.

ESTIGARRIBIA, María. "La buena fe. Implicaciones actuales en las relaciones negociales". En ALBAN, Jorge; CARRANZA, Cesar (Comp.) Estudios de Derecho Privado contemporáneo. Contratos - Teoría General, contratación predispuesta, de consumo y financiera (pp.61-81). Trujillo - Perú: Industria Gráfica Libertad SAC, 2005.

FERNÁNDEZ FERNÁNDEZ, César. Interés compensatorio y moratorio. En: AA.VV. Código Civil Comentado (pp. 407-410). Tomo VI, Lima: Gaceta Jurídica, 2007.

FERREROCOSTA, Raúl. Curso de derecho de Las Obligaciones. Lima: Grijley, 2001. 
FLORES, Carolina; MORALES, Liliana; YÁÑEZ, Álvaro. Interés Máximo Convencional. Origen Evolución y forma de cálculo. Chile: s.e., 2005, Consulta: 15 de diciembre de 2015, en http://www.sbif.cl/sbifweb//internet/ archivos/publicacion_4193.pdf

FALCONÍ PICARDO, Marco; FALCONÍ PICARDO, Angelina. Diccionario de Banca, Finanzas y Empresa. Lima: Grijley, 2002.

GHERSI, Carlos Alberto. Contratos civiles y comerciales. T.II. $4^{\circ}$ Ed. Buenos Aires: ASTREA, 1998.

GONZALES BARRÓN, Günther. "El mito del consumidor razonable". Revista Actualidad Jurídica (pp.19-25). Tomo N²02, 2010, Lima: Gaceta Jurídica, 2010.

GUTIÉRREZ CAMACHO, Walter y CASTRO, Nelwin. "Definición de Mutuo". En AA.VV. Código Civil Comentado (pp. 443-445). Tomo VIII, Lima: Gaceta Jurídica, 2007.

HENRÍQUEZ CRUZ, Guillermo. “La relación contractual consumidor empresa bancaria o financiera en Brasil”. Revista Bibliotecal (pp. 203-227). Año N 5, Diciembre 2002, Lima: Colegio de Abogados de Lima, 2002.

INDECOPI - GERENCIA DE ESTUDIOS ECONÓMICOS. Boletín Estadístico. Año 15, $N^{\circ}$ 147, 2015, Consulta: 22 de enero de 2016, en https://www.indecopi.gob.pe/documents/20182/143803/Abril2015.p df

KEIL, Roberto. Lecciones de derecho Monetario. Lima: Rentería Editores SAC, 2004.

LA REPÚBLICA. Advierten sobre tasas de interés, 2010, 23 de noviembre, p. 17.

LORENZETTI, Ricardo. Derecho contractual. Nuevas formas contractuales. Lima: Palestra Editores, 2001.

MARTÍNEZ NEYRA, Néstor. Sistemas Financieros. Derecho financiero comparado. Bogotá: Biblioteca Felabán, 1994.

MERINO ACUÑA, Roger. "Las asimetrías entre proveedor y consumidor en el marco de la bifurcación de la autonomía contractual ¿de la parte al status?". Revista Jurídica del Perú (p. 251-273), № 77, Lima: Gaceta jurídica, 2007.

MEZA FINOCHETTI, Roberto. "El contrato de mutuo". Normas legales. Legislación y doctrina, (p. A43-A50), № 275, Trujillo-Perú: Normas Legales, 1998.

Osterling PARODI, Felipe; CASTILlO FreYre, Mario. Tratado de las Obligaciones. Volumen XVI ( $2^{\circ}$ Parte-Tomo V). Lima: Fondo Editorial PUCP, 1996. 
REBOlLEDO ABANTO, Paúl; SOTO ChÁVEZ, Robert. Estructura del mercado de créditos y tasas de interés: una aproximación al segmento de las microfinanzas. Perú: BCRP, 2004. Consulta: 30 de enero de 2009, en http://www.bcrp/docs/publicaciones/documentos.detrabajo/2004/documento-trabajo-7-2004.pdf

REZZÓNICO, Juan. Principios fundamentales de los contratos. Buenos Aires: ASTREA, 1999.

RODRÍGUEZ AZUERO, Sergio. Contratos Bancarios. Su significación en América Latina. $4^{\circ}$ Reimp. de la $2^{\circ}$ ed., Colombia: Legis, 2008.

SEBASTIÁN BAROCHELLI, Sergio (s.a.). El concepto de Consumidor en el nuevo Código Civil y Comercial. [En Línea] Consulta: 22 de enero de 2016. http://www.nuevocodigocivil.com/wpcontent/uploads/2015/08/El-concepto-de-consumidor-en-elnuevo-CCyC-por-Barocelli1.pdf

SUPERINTENDENCIA DE BANCA, SEgUROS Y AFP. Tasas de interés promedio. Consulta: 29 de febrero de 2016, en http:// www.sbs.gob.pe/principal/categoria/tasa-de-interespromedio/154/c-154 